Research Article

\title{
Single-Dose Toxicity Study on ML171, a Selective NOX1 Inhibitor, in Mice
}

\author{
Se-Hyun Oh, ${ }^{1,2}$ Ji-Sun Ahn, ${ }^{1}$ Eun-Joo Oh, ${ }^{1}$ You-Jin Kim, ${ }^{1,2}$ Ju-Min Yook, ${ }^{1}$ \\ Jeong-Hoon Lim, ${ }^{1,3}$ Hee-Yeon Jung, ${ }^{1,3}$ Ji-Young Choi, ${ }^{1,3}$ Chan-Duck Kim, ${ }^{1,3}$ Sun-Hee Park, ${ }^{1,3}$ \\ Yong-Lim Kim, ${ }^{1,3}$ and Jang-Hee Cho $\mathbb{D}^{1,3}$ \\ ${ }^{1}$ Division of Nephrology, Department of Internal Medicine, School of Medicine, Kyungpook National University, Kyungpook National \\ University Hospital, Daegu 41944, Republic of Korea \\ ${ }^{2}$ Cell and Matrix Research Institute, Kyungpook National University, Daegu 41944, Republic of Korea \\ ${ }^{3}$ Department of Internal Medicine, School of Medicine, Kyungpook National University, Daegu 41944, Republic of Korea
}

Correspondence should be addressed to Jang-Hee Cho; jh-cho@knu.ac.kr

Received 7 January 2021; Revised 1 April 2021; Accepted 15 May 2021; Published 30 May 2021

Academic Editor: Elena Baralla

Copyright (c) 2021 Se-Hyun Oh et al. This is an open access article distributed under the Creative Commons Attribution License, which permits unrestricted use, distribution, and reproduction in any medium, provided the original work is properly cited.

\begin{abstract}
Background. ML171 is a potent nicotinamide adenine dinucleotide phosphate oxidase (NOX) inhibitor with isoform selectivity only for NOX1. This study is aimed at investigating the safety of ML171 after a single intraperitoneal (IP) injection in mice. Methods. The toxicity of a single dose of ML171 was evaluated in 6-week-old Institute of Cancer Research (ICR) mice in a good laboratory practice (GLP) laboratory. Twenty-five mice of each sex were assigned to five groups: negative control, vehicle control, and 125, 250, and $500 \mathrm{mg} / \mathrm{kg}$ of ML171. All mice were acclimatized for one week before beginning the study. Mice received an IP injection of ML171 or vehicle. The general condition and mortality of the animals were observed. The mice were sacrificed to evaluate histopathology 14 days after the administration of ML171 or vehicle. Results. Bodyweights were not significantly different in any group. Three males and one female died due to ML171 administration in the $500 \mathrm{mg} / \mathrm{kg}$ dose group. Autopsies of the surviving mice did not reveal any significant abnormalities after the injection of $125 \mathrm{mg} / \mathrm{kg}$ of ML171. However, the anterior lobe edge of the liver was thickened and adhesions between the liver and adjacent organs were observed in mice treated with 250 or $500 \mathrm{mg} / \mathrm{kg}$ of ML171. In addition, hypertrophy of centrilobular hepatocytes and inflammatory cell infiltration were observed after injection of 250 and $500 \mathrm{mg} / \mathrm{kg}$ of ML171. Conclusion. Our results indicate that the lethal IP injection dose of ML171 is $500 \mathrm{mg} / \mathrm{kg}$ for both males and females. Mortality were not observed for lower doses of ML171. The safe dose of single IP ML171 in ICR mice was $250 \mathrm{mg} / \mathrm{kg}$ or less. Further studies are needed to confirm the safety of ML171 in the human body.
\end{abstract}

\section{Introduction}

The nicotinamide adenine dinucleotide phosphate oxidase (NOX) family catalyzes reactive oxygen species (ROS) $[1,2]$. NOX generates ROS, which play a role in a growing number of diseases, including cancer, atherosclerosis, hypertension, neurological disorders, and inflammation [3-5]. Among the NOX inhibitors, ML171 is a potent, selective inhibitor of NOX1, with an IC50 of 129-156 nM in cell-based assays. ML171 blocks NOX1-dependent ROS generation, with only marginal inhibitory effects on other cellular ROS-producing enzymes and receptors, including the other NOX isoforms [6].
ML171 is effective in inhibiting oxidative stress $[7,8]$. The antioxidant effects of ML171 have been studied in a variety of physiological and pathological processes, including the development and effects of severe hypertension, metastasis of hepatocellular carcinoma, and glial activation with crosstalk control [9-11]. Recently, we confirmed the renoprotective effect of ML171 in an ischemia-reperfusion injury (IRI) mouse model. ML171 attenuated kidney IRI via inhibition of ROS-mediated Extracellular Signal-Regulated Kinase (ERK) signaling and reduced oxidative stress-induced apoptosis in renal tubule cells [12]. These results suggest that ML171 could be used as a therapeutic agent for oxidative injury in many different organs. 
In a preclinical study, we treated animals with a $60 \mathrm{mg} / \mathrm{kg}$ intraperitoneal (IP) injection of ML171. The IP injection was well tolerated in all the mice without any adverse events and histological changes [12]. However, the experiments were not performed in a good laboratory practice (GLP) setting. A more objective and systematic verification of ML171 safety was needed before human clinical trials. This study is aimed at investigating the safety of ML171 after a single IP injection in mice in compliance with GLP and at determining the approximate lethal dose of ML171.

\section{Materials and Methods}

2.1. Study Approval. Animal experiments were conducted by Biotoxtech (Cheongwon, Korea, Biotoxtech study number B20052) in accordance with the guidelines of the Food and Drug Administration (KFDA, 2017) and the Principles of Good Laboratory Practices of the Organization for Economic Cooperation and Development (OECD, 1998) [13]. All experiments and histology analysis were performed according to that "ICH Harmonised Tripartite Guideline, M3 (R2), Guidance on Nonclinical Safety Studies for the Conduct of Human Clinical Trials and Marketing Authorization for Pharmaceuticals" [14]. Approval for this study was granted from the Institutional Animal Ethics Committee of Biotoxtech (200133).

\subsection{Preparation of ML171 and Vehicle Control Solutions. The} ML171 (2-acetylphenothiazine; HY-12805, MedChemExpress, U.S.A.) was weighed and placed in a preparation bottle. The drug was dissolved in a sterile solution of $10 \%$ DMSO (K50270931, Merck, Germany), 40\% PEG300 (BCCB1565, Sigma-Aldrich, Co., USA), and 5\% Tween-80 (BCBV8843, Sigma-Aldrich, Co., USA) in physiological saline (19092, JW Pharmaceutical Co., Ltd., Korea). The vehicle control material was $10 \%$ DMSO, 40\% PEG300, and 5\% Tween- 80 in physiological saline. The ML171 and vehicle solution were prepared just before administration.

2.3. Single-Dose IP Toxicity Test of ML171 in Mice. Six-week-old female and male Institute of Cancer Research (ICR) mice were used for the study (Orient Bio Inc., Seongnam, Korea). After a one-week acclimatization period, the bodyweight and general health were checked to confirm no abnormalities in all animals. Male and female (25 each) mice with similar bodyweights were selected and divided into five groups as follows: G1/0, negative control; G2/0, vehicle control; G3/125, $125 \mathrm{mg} / \mathrm{kg}$ of ML171; G4, $250 \mathrm{mg} / \mathrm{kg}$ of ML171; and G5, $500 \mathrm{mg} / \mathrm{kg}$ of ML171. Animals were randomly assigned to groups, so the average weights were similar between groups.

ML171 was administered by an IP injection to evaluate abdominal cavity exposure to the drug. The injection volume for each individual was calculated based on the bodyweight before administering the injection. The injection volume was $20 \mathrm{ml} / \mathrm{kg}$, and the doses were $125 \mathrm{mg} / \mathrm{kg}, 250 \mathrm{mg} / \mathrm{kg}$, and $500 \mathrm{mg} / \mathrm{kg}$. The dosage was based on preliminary data, and the dosages were selected in a range in which no mortality was observed in preliminary experiments. The same amount of physiological saline or vehicle (10\% DMSO, $40 \%$
PEG300, and 5\% Tween-80) was administered to the control and vehicle control groups, respectively.

2.4. General Observation and Histopathological Analysis of Mice. General health, including the type of toxic symptoms, time of onset, and recovery time, was evaluated at 1, 2, 4, and 6 hours after drug or vehicle administration. General health was examined once daily for 14 days after the first day of drug administration. Deaths were recorded. Bodyweight was measured before drug administration and 4, 8, and 15 days after administration (autopsy day). If a dead animal was observed during the observation period, the bodyweight was measured on the day of death and the animal was autopsied within 24 hours. All surviving mice were sacrificed at 15 days, and histological examinations were performed. Gross findings were recorded during the autopsy, and a histopathological examination with hematoxylin and eosin (H\&E) staining of the liver was performed [15].

2.5. Statistical Analysis. Data are expressed as the mean \pm standard deviation for the bodyweight and numbers for the number of mice. Bartlett's test was performed to test for an equal variance of the bodyweight. In the case of equal variance, significance was confirmed by one-way analysis of variance. Mortality, the incidence of macroscopic or microscopic findings in the liver, was analyzed by a chi-square test. The statistical analysis was performed using Statistical Analysis System (SAS) (version 9.3, SAS Institute Inc., USA). $p<0.05$ was considered statistically significant.

\section{Results}

3.1. Effects of ML171 on Bodyweight. Bodyweight changes for male and female mice are summarized in Table 1 . The ML171 groups, including G3/125, G4/250, and G5/500, showed comparable bodyweight changes compared to the G1/0 and G2/0 groups (Figure 1). There were no significant differences $(p>0.05)$ in the bodyweights among male or female groups throughout the study.

3.2. Effects of ML171 on General Health and Mortality. During the observation period, no abnormalities in general health were observed in either male or female mice in the $\mathrm{G} 1 / 0, \mathrm{G} 2 / 0, \mathrm{G} 3 / 125$, and G4/250 groups. In the G3/125 group, one male mouse showed yellow-colored mucous stool $0.5,1$, and 4 hours after administration. Two female mice in the G3/125 group also showed mucous stools 0.5 hours after administration.

Three males in the G5/500 group exhibited decreased locomotor activity and fecal volume with tremor two days after administration. All three mice died on the third day after injection and were found prone or lying on their side (Table 2). Two females in the G5/500 group also showed a decrease in fecal volume and tremor on the second day after drug administration. Decreased spontaneous movement with irregular respiration was observed on the third day in one of the mice, and the mouse died on the fourth day after drug injection. During the observation period, individual clinical signs of all mice are detailed in Supplementary Table 1. 
TABle 1: Mean bodyweights.

\begin{tabular}{|c|c|c|c|c|c|c|}
\hline \multirow{2}{*}{ Sex } & \multirow{2}{*}{\multicolumn{2}{|c|}{$\begin{array}{c}\text { Group/dose } \\
(\mathrm{mg} / \mathrm{kg})\end{array}$}} & \multicolumn{4}{|c|}{ Day } \\
\hline & & & 1 & 4 & 8 & 15 \\
\hline \multirow{15}{*}{ Male } & \multirow{3}{*}{$\mathrm{G} 1 / 0$} & Mean & 30.3 & 30.8 & 31.5 & 33.5 \\
\hline & & $\mathrm{SD}$ & 0.7 & 0.7 & 0.9 & 1.6 \\
\hline & & $N$ & 5 & 5 & 5 & 5 \\
\hline & \multirow{3}{*}{$\mathrm{G} 2 / 0$} & Mean & 0.2 & 30.1 & 31.6 & 33.4 \\
\hline & & SD & 1.2 & 2.1 & 1.8 & 1.8 \\
\hline & & $N$ & 5 & 5 & 5 & 5 \\
\hline & \multirow{3}{*}{ G3/125 } & Mean & 30.5 & 30.5 & 31.4 & 33.6 \\
\hline & & SD & 1.7 & 1.7 & 1.8 & 1.9 \\
\hline & & $N$ & 5 & 5 & 5 & 5 \\
\hline & \multirow{3}{*}{ G4/250 } & Mean & 30.4 & 30.2 & 31.5 & 33.4 \\
\hline & & $\mathrm{SD}$ & 1.2 & 1.4 & 1 & 2.2 \\
\hline & & $N$ & 5 & 5 & 5 & 5 \\
\hline & \multirow{3}{*}{ G5/500 } & Mean & 30.4 & 30.8 & 33.0 & 35.4 \\
\hline & & $\mathrm{SD}$ & 1.4 & 0.2 & 1.5 & 0.6 \\
\hline & & $N$ & 5 & 2 & 2 & 2 \\
\hline \multirow{15}{*}{ Female } & \multirow{3}{*}{$\mathrm{G} 1 / 0$} & Mean & 22.8 & 22.9 & 24.3 & 26.3 \\
\hline & & SD & 1.8 & 1.3 & 2.1 & 1.1 \\
\hline & & $N$ & 5 & 5 & 5 & 5 \\
\hline & \multirow{3}{*}{$\mathrm{G} 2 / 0$} & Mean & 22.9 & 22.0 & 23.8 & 25.8 \\
\hline & & SD & 0.9 & 0.3 & 1.0 & 1.7 \\
\hline & & $N$ & 5 & 5 & 5 & 5 \\
\hline & \multirow{3}{*}{ G3/125 } & Mean & 22.6 & 23.3 & 24.6 & 26.9 \\
\hline & & $\mathrm{SD}$ & 1.5 & 1.4 & 1.9 & 1.7 \\
\hline & & $N$ & 5 & 5 & 5 & 5 \\
\hline & \multirow{3}{*}{$\mathrm{G} 4 / 250$} & Mean & 22.6 & 22.4 & 24.2 & 25.5 \\
\hline & & $\mathrm{SD}$ & 1.4 & 1.1 & 1.0 & 1.2 \\
\hline & & $N$ & 5 & 5 & 5 & 5 \\
\hline & \multirow{3}{*}{ G5/500 } & Mean & 22.9 & 22.4 & 24.7 & 26.2 \\
\hline & & SD & 1.4 & 2.2 & 1.0 & 1.6 \\
\hline & & $\mathrm{N}$ & 5 & 4 & 4 & 4 \\
\hline
\end{tabular}

G1: negative control; G2: vehicle control. Data represent the mean \pm SD, and no significant difference was found in one-way analysis of variance $(p>0.05)$.

3.3. Effects of ML171 on Autopsy Findings. Autopsies of the dead mice showed no gross abnormalities. In the surviving cases, no gross abnormalities were observed in either male or female mice from the G1/0, G2/0, and G3/125 groups. However, thickening in the anterior lobular edge of the liver was observed in mice from the G4/250 and G5/500 groups. In addition, liver adhesions with the adjacent stomach, kidney, and diaphragm were observed in the G4/250 and G5/500 groups (Table 3). There were no significant differences $(p>0.05)$ in the frequency of macroscopic abnormalities among groups.

3.4. Effects of ML171 on the Histology of Injection Sites. Histology of the liver revealed mild to moderate hypertrophy of centrilobular hepatocytes in three males and one female in the G4/250 group and all males and two females in the G5/500 group. This finding correlated with the lobe thickening observed in the autopsy. Hepatocyte mitosis increased in two males and one female in the G4/250 group and all males and three females in the G5/500 group. In addition, mild fibrosis of the membrane and inflammatory cell infiltration were observed in all mice from the G4/250 and G5/500 groups. The frequency of microscopic abnormalities did not differ significantly $(p>0.05)$ among groups (Table 4$)$. The fibrosis and inflammation were associated with the liver adhesions to adjacent organs and tissues in the abdominal cavity. Representative images and the frequency of the findings are shown in Figure 2 and Table 4, respectively.

\section{Discussion}

We investigated the safety of a single IP injection of ML171 in a GLP laboratory. Bodyweight was not affected by the administration of ML171 at any of the doses. However, four mice $(40 \%)$ treated with $500 \mathrm{mg} / \mathrm{kg}$ of ML171 died. The autopsies of the surviving cases did not reveal any significant abnormalities in the control and G3/125 groups. However, the anterior lobe edge of the liver was thickened and adhesions of the liver with adjacent organs were observed in the G4/250 and G5/500 groups. In addition, hypertrophy of centrilobular hepatocytes and inflammatory cell infiltration were observed in the G4/250 and G5/500 groups. These results suggest that the safe dose of single IP ML171 in ICR mice was $250 \mathrm{mg} / \mathrm{kg}$ or less.

The single-dose toxicity test study determines toxic phenomena occurring within a short time after a single test substance administration. This test confirms a safe single dose that does not cause adverse events or life-threatening effects to the animal. The present test was conducted to evaluate IP injection toxicity and obtain a lethal dose of ML171. Forty percent of ICR mice were injected with $500 \mathrm{mg} / \mathrm{kg}$ of ML171 died, whereas mortality was not observed in the lower dose groups. Injection of $250 \mathrm{mg} / \mathrm{kg}$ of ML171 caused macroscopic changes, such as thickening of the lobular edge of the liver and adhesion of the liver to surrounding organs, which corresponded to microscopic abnormalities. A dose higher than $250 \mathrm{mg} / \mathrm{kg}$ of ML171 might induce more toxicity in mice; therefore, $250 \mathrm{mg} / \mathrm{kg}$ is the highest dose of ML171 to expect efficacy without significant adverse effects such as mortality.

Among the seven NOX isoforms [16], NOX1-dependent ROS production contributes to cellular growth signaling, angiogenesis, motility, and endothelial function [17-19]. NOX1 is a therapeutic target for IRI of multiple organs, including the heart, lung, kidney, and retina [12, 20-22]. ML171, a selective NOX1 inhibitor, has been studied in various animal models [11,23, 24]. The route of ML171 administration was a single IP injection, ranging between 20 and $60 \mathrm{mg} / \mathrm{kg}$. The present single-dose toxicity study tested the safety of a single IP administration of ML171 with a range between $125-500 \mathrm{mg} / \mathrm{kg}$. Therefore, we secured the safety evidence for a single IP dosing of ML171. However, further safety toxicity tests, such as long-term recovery tests and repeated dose toxicity tests, are needed to provide more safety data.

Autopsies of mice treated with higher ML171 doses revealed a thickening of the anterior hepatic lobes. The anterior location may have been directly exposed to the injected 


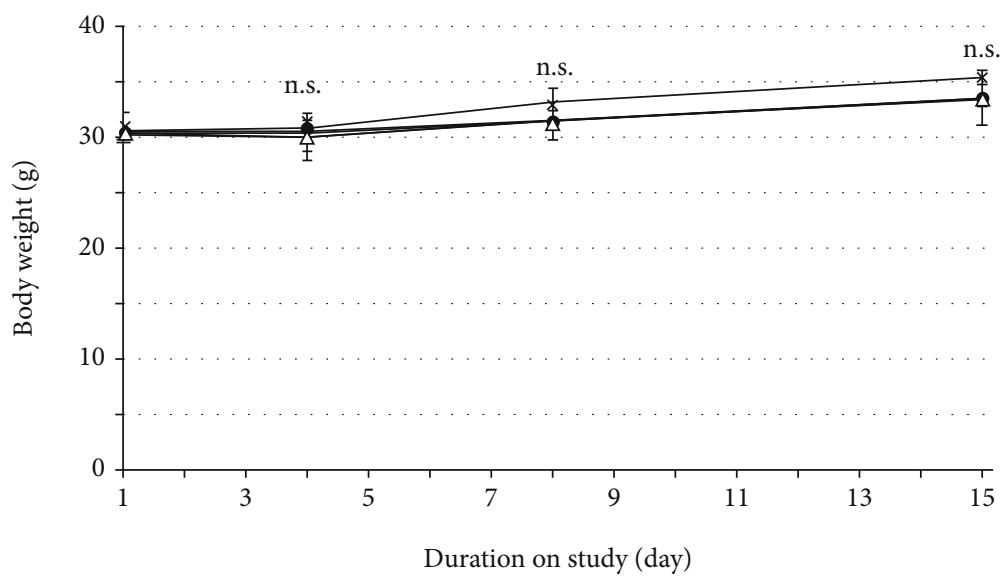

G1: Negative control, G2: Vechile control

(a)

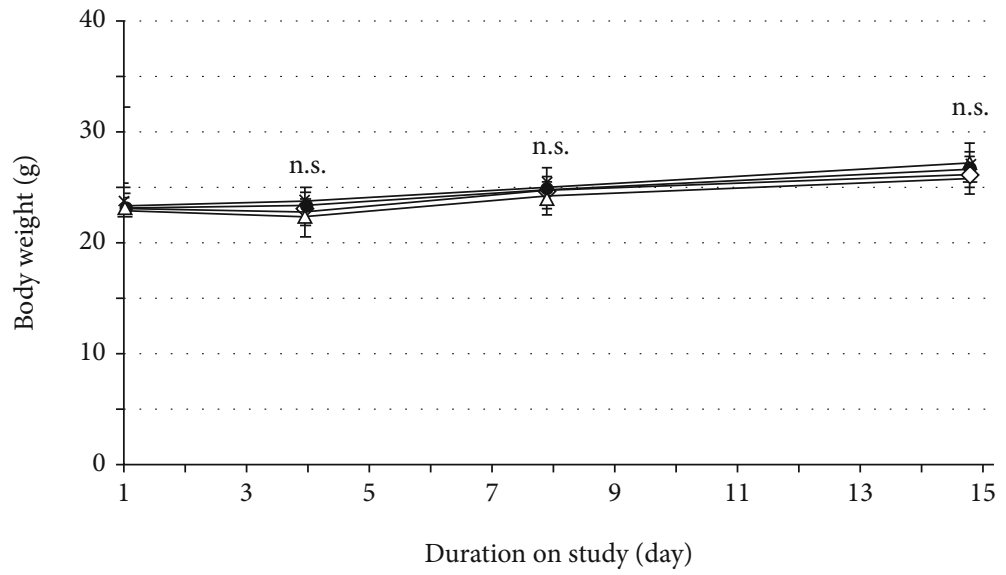

G1: Negative control, G2: Vechile control

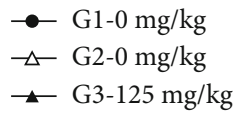

$\prec-\mathrm{G} 4-250 \mathrm{mg} / \mathrm{kg}$

$\star \mathrm{G} 5-500 \mathrm{mg} / \mathrm{kg}$

(b)

FIGURE 1: Bodyweights in male (a) and female (b) mice after a single injection of ML171 or vehicle. G1/0 is the untreated control group, and G2/0 is the vehicle-treated group. The G3/125, G4/250, and G5/500 groups were treated with the indicated dose of ML171. The $x$-axis indicates days after injection. Data represent the mean $\pm \mathrm{SD}$, and there is no significant difference in one-way analysis of variance $(p>0.05)$. n.s.: not significant.

TABLE 2: Summary of mortality.

\begin{tabular}{|c|c|c|c|c|c|c|c|c|c|c|c|c|c|c|c|c|c|c|}
\hline \multirow{2}{*}{ Sex } & \multirow{2}{*}{ Group/dose $(\mathrm{mg} / \mathrm{kg})$} & \multirow{2}{*}{ No. of animals } & \multicolumn{15}{|c|}{ Day after treatment } & \multirow{2}{*}{ Mortality } \\
\hline & & & 1 & 2 & 3 & 4 & 5 & 6 & 7 & 8 & 9 & 10 & 11 & 12 & 13 & 14 & 15 & \\
\hline \multirow{5}{*}{ Male } & $\mathrm{G} 1 / 0$ & 5 & $* 0$ & 0 & 0 & 0 & 0 & 0 & 0 & 0 & 0 & 0 & 0 & 0 & 0 & 0 & 0 & ${ }^{\#} 0 / 5$ \\
\hline & $\mathrm{G} 2 / 0$ & 5 & 0 & 0 & 0 & 0 & 0 & 0 & 0 & 0 & 0 & 0 & 0 & 0 & 0 & 0 & 0 & $0 / 5$ \\
\hline & $\mathrm{G} 3 / 125$ & 5 & 0 & 0 & 0 & 0 & 0 & 0 & 0 & 0 & 0 & 0 & 0 & 0 & 0 & 0 & 0 & $0 / 5$ \\
\hline & G4/250 & 5 & 0 & 0 & 0 & 0 & 0 & 0 & 0 & 0 & 0 & 0 & 0 & 0 & 0 & 0 & 0 & $0 / 5$ \\
\hline & G5/500 & 5 & 0 & 0 & 3 & 0 & 0 & 0 & 0 & 0 & 0 & 0 & 0 & 0 & 0 & 0 & 0 & $3 / 5$ \\
\hline \multirow{5}{*}{ Female } & $\mathrm{G} 1 / 0$ & 5 & 0 & 0 & 0 & 0 & 0 & 0 & 0 & 0 & 0 & 0 & 0 & 0 & 0 & 0 & 0 & $0 / 5$ \\
\hline & $\mathrm{G} 2 / 0$ & 5 & 0 & 0 & 0 & 0 & 0 & 0 & 0 & 0 & 0 & 0 & 0 & 0 & 0 & 0 & 0 & $0 / 5$ \\
\hline & G3/125 & 5 & 0 & 0 & 0 & 0 & 0 & 0 & 0 & 0 & 0 & 0 & 0 & 0 & 0 & 0 & 0 & $0 / 5$ \\
\hline & $\mathrm{G} 4 / 250$ & 5 & 0 & 0 & 0 & 0 & 0 & 0 & 0 & 0 & 0 & 0 & 0 & 0 & 0 & 0 & 0 & $0 / 5$ \\
\hline & G5/500 & 5 & 0 & 0 & 0 & 1 & 0 & 0 & 0 & 0 & 0 & 0 & 0 & 0 & 0 & 0 & 0 & $1 / 5$ \\
\hline
\end{tabular}

G1: negative control; G2: vehicle control. * Number of dead mice. ${ }^{*}$ Number of with mortality/total mice. 
TABLE 3: Incidence of macroscopic findings in the liver.

(a)

\begin{tabular}{|c|c|c|c|c|c|}
\hline \multirow[b]{2}{*}{ Group/dose (mg/kg) } & \multicolumn{5}{|c|}{ Male } \\
\hline & $\begin{array}{c}\text { G1/0 } \\
\text { Negative control }\end{array}$ & $\begin{array}{c}\mathrm{G} 2 / 0 \\
\text { Vehicle control }\end{array}$ & $\begin{array}{l}\text { G3/125 } \\
\text { Low dose }\end{array}$ & $\begin{array}{l}\text { G4/250 } \\
\text { Mid dose }\end{array}$ & $\begin{array}{l}\text { G5/500 } \\
\text { High dose }\end{array}$ \\
\hline Number examined & 5 & 5 & 5 & 5 & 2 \\
\hline \multicolumn{6}{|l|}{ Liver } \\
\hline Thickening, lobar edge, all lobes & ${ }^{*} 0$ & 0 & 0 & 5 & 2 \\
\hline Total number of affected animals & \# $0 / 5$ & $0 / 5$ & $0 / 5$ & $5 / 5$ & $2 / 2$ \\
\hline $\begin{array}{l}\text { Adhesion, to adjacent organs/tissues } \\
\text { (stomach, diaphragm) }\end{array}$ & ${ }^{*} 0$ & 0 & 0 & 5 & 2 \\
\hline Total number of affected animals & ${ }^{\#} 0 / 5$ & $0 / 5$ & $0 / 5$ & $5 / 5$ & $2 / 2$ \\
\hline
\end{tabular}

(b)

\begin{tabular}{|c|c|c|c|c|c|}
\hline \multirow[b]{2}{*}{ Group/dose (mg/kg) } & \multicolumn{5}{|c|}{ Female } \\
\hline & $\begin{array}{c}\text { G1/0 } \\
\text { Negative control }\end{array}$ & $\begin{array}{c}\mathrm{G} 2 / 0 \\
\text { Vehicle control }\end{array}$ & $\begin{array}{l}\text { G3/125 } \\
\text { Low dose }\end{array}$ & $\begin{array}{l}\text { G4/250 } \\
\text { Mid dose }\end{array}$ & $\begin{array}{l}\text { G5/500 } \\
\text { High dose }\end{array}$ \\
\hline Number examined & 5 & 5 & 5 & 5 & 4 \\
\hline \multicolumn{6}{|l|}{ Liver } \\
\hline Thickening, lobar edge, all lobes & ${ }^{*} 0$ & 0 & 0 & 5 & 4 \\
\hline Total number of affected animals & \#0/5 & $0 / 5$ & $0 / 5$ & $5 / 5$ & $4 / 5$ \\
\hline $\begin{array}{l}\text { Adhesion, to adjacent organs/tissues } \\
\text { (stomach, diaphragm) }\end{array}$ & ${ }^{*} 0$ & 0 & 0 & 5 & 4 \\
\hline Total number of affected animals & ${ }^{\#} 0 / 5$ & $0 / 5$ & $0 / 5$ & $5 / 5$ & $4 / 5$ \\
\hline
\end{tabular}

${ }^{*}$ Number of affected mice on liver. ${ }^{*}$ Number of with affected mice/total mice. Data was no significant difference after using the chi-square test (all $p>0.05$ ).

TABLE 4: Incidence and severity of microscopic findings in the liver.

\begin{tabular}{|c|c|c|c|c|}
\hline \multirow[b]{2}{*}{ Group/dose (mg/kg) } & \multicolumn{2}{|c|}{ Male } & \multicolumn{2}{|c|}{ Female } \\
\hline & $\begin{array}{l}\text { G4/250 } \\
\text { Mid dose }\end{array}$ & $\begin{array}{l}\text { G5/500 } \\
\text { High dose }\end{array}$ & $\begin{array}{l}\text { G4/250 } \\
\text { Mid dose }\end{array}$ & $\begin{array}{l}\text { G5/500 } \\
\text { High dose }\end{array}$ \\
\hline Number examined & 5 & 2 & 5 & 4 \\
\hline \multicolumn{5}{|l|}{ Liver } \\
\hline \multicolumn{5}{|l|}{$\begin{array}{l}\text { Fibrosis, capsular, with inflammatory cell } \\
\text { infiltrate }\end{array}$} \\
\hline Minimal & $* 5$ & 2 & 5 & 4 \\
\hline Total number of affected animals & ${ }^{\#} 5 / 5$ & $2 / 2$ & $5 / 5$ & $4 / 4$ \\
\hline \multicolumn{5}{|l|}{ Increased mitosis, hepatocyte } \\
\hline Minimal & $* 2$ & 2 & 1 & 3 \\
\hline Total number of affected animals & ${ }^{\#} 2 / 5$ & 2 & 1 & 3 \\
\hline \multicolumn{5}{|l|}{ Hypertrophy, hepatocyte, centrilobular } \\
\hline Minimal & $* 2$ & 0 & 1 & 1 \\
\hline Slight & ${ }^{*} 1$ & 2 & 0 & 1 \\
\hline Total number of affected animals & ${ }^{\#} 3 / 5$ & $2 / 2$ & $1 / 5$ & $2 / 4$ \\
\hline
\end{tabular}

${ }^{*}$ Number of affected mice on the liver. ${ }^{*}$ Number of with affected mice/total mice. Data was no significant difference after using the chi-square test (all $p>0.05$ ).

ML171. The lobe thickening correlated with the histologic finding of hepatocyte hypertrophy. Macroscopic liver adhesions to the surrounding organs were confirmed by fibrosis of the membranes and inflammatory cell infiltration. These changes, along with the increased hepatocyte mitosis, are generally regarded as a repair response after haptic injury and hepatocyte loss [25]. Additional blood tests are required to evaluate the degree of liver damage. However, we did not find any macroscopic and microscopic abnormalities in mice after injection with $125 \mathrm{mg} / \mathrm{kg}$ of ML171. Liang et al. reported 


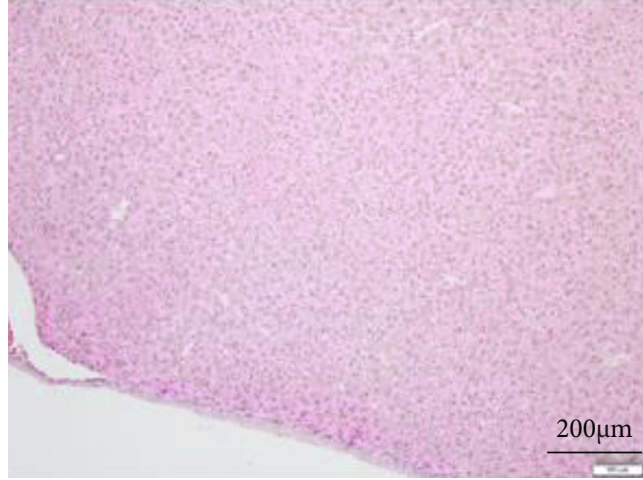

(a)

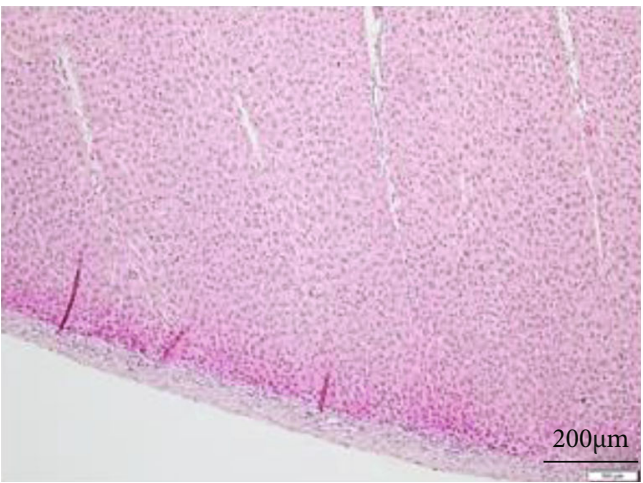

(c)

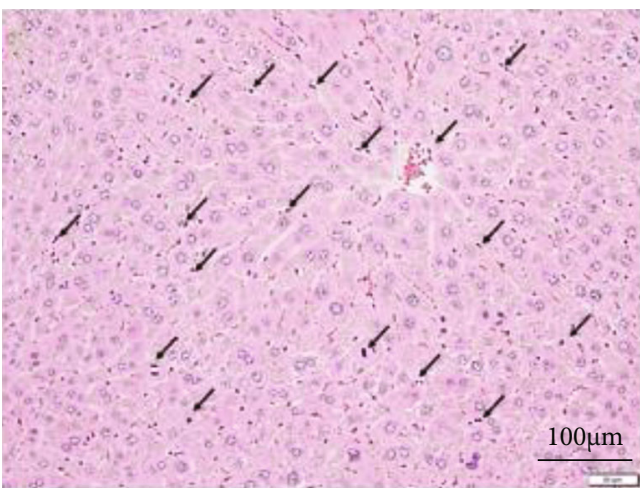

(e)

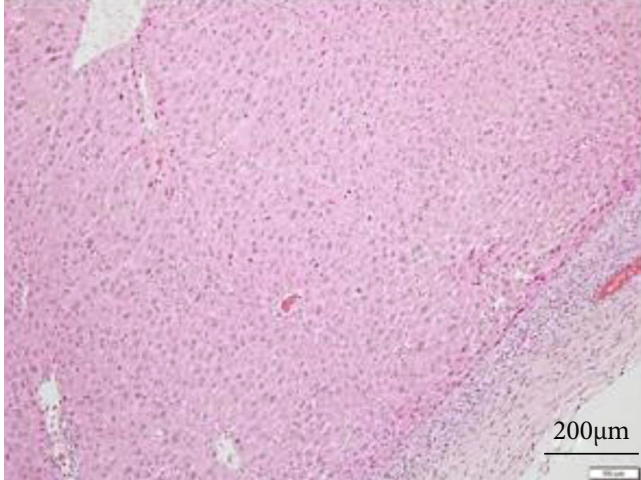

(b)

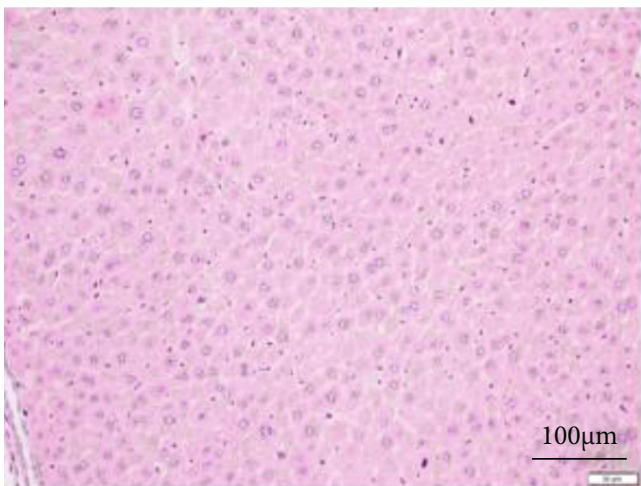

(d)

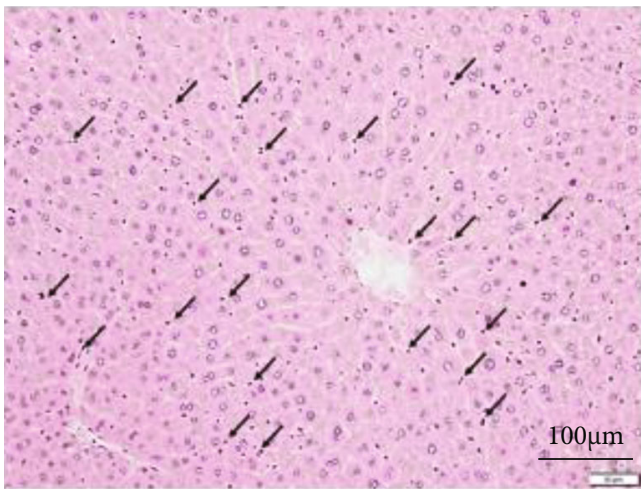

(f)

Figure 2: Histology of the liver. G1/0 (a, d) is vehicle control groups. Mild fibrosis of the membrane and inflammatory cell infiltration were observed in the G4/250 (b) and G5/500 (c) groups. Hepatocytes were hypertrophic in centrilobular areas and increased mitosis occurred in the G4/250 (e) and G5/500 (f) groups.

no other liver pathology after multiple injections of ML171 in mice with hepatocellular carcinoma [10]. In Liang et al.'s study, ML171 was administered intraperitoneally twice weekly for four weeks. Together with the present study, these results demonstrate the long-term safety of ML171 in terms of hepatotoxicity.

Sexual differences in toxic symptoms occur in response to some drugs [26, 27]. Thus, we evaluated both male and female mice in the present study. The bodyweight consistently increased over time in both male and female mice. Adverse symptoms and mortality were not significantly different between the sexes. Furthermore, macroscopic and microscopic findings observed in the G4/250 and G5/500 groups occurred in both males and females. Our results suggest that ML171 toxicities are not associated with sex and the lethal dose is not different between males and females.

There are several limitations to the present study. As described above, recovery tests and repeated dose toxicity tests should be performed to evaluate the long-term effects of ML171. Further studies should include a biochemical analysis of the $250 \mathrm{mg} / \mathrm{kg}$ dose, which induced some histologic changes to the liver. The detailed doses between 125 and 250 should be explored to identify the true cutoff for toxic outcomes. If persistent liver damage is observed, an analysis of the underlying mechanism should also be performed. Nevertheless, our research is the first study to demonstrate 
the safety of a single ML171 injection and the lethal dose for IP injection of ML171 in a mouse model. These data form the basis for future long-term experiments with ML171.

\section{Conclusions}

The results of this study indicate that the lethal IP dose of ML171 is $500 \mathrm{mg} / \mathrm{kg}$ for both males and females. Mortality was not observed in doses up to $250 \mathrm{mg} / \mathrm{kg}$ of ML171. Thus, the safe dose of single IP ML171 in ICR mice was $250 \mathrm{mg} / \mathrm{kg}$ or less. Further studies are needed to confirm the safety of ML171 in the human body.

\section{Data Availability}

The data that support the findings of this study are available from the corresponding author upon reasonable request.

\section{Conflicts of Interest}

The authors declare no conflict of interest.

\section{Authors' Contributions}

$\mathrm{S}-\mathrm{HO}$ and J-HC are responsible for the conceptualization. S$\mathrm{HO}, \mathrm{J}-\mathrm{SA}, \mathrm{E}-\mathrm{JO}, \mathrm{Y}-\mathrm{JK}$, and J-HC did the methodology. S-HO, J-SA, E-JO, Y-JK, J-MY, and J-HC did the formal analysis. SHO, J-HL, H-YJ, J-YC, C-DK, S-HP, Y-LK, and J-HC the investigation. S-HO, J-SA, E-JO, Y-JK, and J-HC curated the data. S-HO and J-HC are assigned to the writing and original draft preparation. S-HO and J-HC are assigned to the writing of the review and editing. All authors have read and agreed to the published version of the manuscript.

\section{Acknowledgments}

This research was supported by Medi-Start Up Program funded by the Daegu Metropolitan City (Project Name: Development of the candidate agents for acute kidney injury through the reduction of oxidative stress), and supported by Basic Science Research Program through the National Research Foundation of Korea (NRF) funded by the Ministry of Education (2020R1I1A3068253 and 2020R1I1A1A01055554).

\section{Supplementary Materials}

Supplemental Table 1: individual clinical signs. (Supplementary Materials)

\section{References}

[1] K. Bedard and K. H. Krause, "The NOX family of ROSgenerating NADPH oxidases: physiology and pathophysiology," Physiological Reviews, vol. 87, no. 1, pp. 245-313, 2007.

[2] F. Magnani and A. Mattevi, "Structure and mechanisms of ROS generation by NADPH oxidases," Current Opinion in Structural Biology, vol. 59, pp. 91-97, 2019.

[3] D. Gianni et al., Probe Reports from the NIH Molecular Libraries Program, 2010.
[4] J. D. Lambeth, "Nox enzymes, ROS, and chronic disease: an example of antagonistic pleiotropy," Free Radical Biology \& Medicine, vol. 43, no. 3, pp. 332-347, 2007.

[5] Y. Zhang, P. Murugesan, K. Huang, and H. Cai, "NADPH oxidases and oxidase crosstalk in cardiovascular diseases: novel therapeutic targets," Nature Reviews Cardiology, vol. 17, no. 3, pp. 170-194, 2020.

[6] D. Gianni, N. Taulet, H. Zhang et al., "A novel and specific NADPH oxidase-1 (Nox1) small-molecule inhibitor blocks the formation of functional invadopodia in human colon cancer cells," ACS Chemical Biology, vol. 5, no. 10, pp. 981-993, 2010.

[7] M. Sela, G. Tirza, O. Ravid et al., "NOX1-induced accumulation of reactive oxygen species in abdominal fat-derived mesenchymal stromal cells impinges on long-term proliferation," Cell Death \& Disease, vol. 6, no. 4, article e1728, 2015.

[8] J. R. Weaver, W. Grzesik, and D. A. Taylor-Fishwick, "Inhibition of NADPH oxidase-1 preserves beta cell function," Diabetologia, vol. 58, no. 1, pp. 113-121, 2015.

[9] A. P. Harvey, A. C. Montezano, K. Y. Hood et al., "Vascular dysfunction and fibrosis in stroke-prone spontaneously hypertensive rats: the aldosterone-mineralocorticoid receptor-Nox1 axis," Life Sciences, vol. 179, pp. 110-119, 2017.

[10] S. Liang, H. Y. Ma, Z. Zhong et al., "NADPH oxidase 1 in liver macrophages promotes inflammation and tumor development in mice," Gastroenterology, vol. 156, pp. 1156-1172.e6, 2019.

[11] S. Kumar and M. Vinayak, "NADPH oxidase1 inhibition leads to regression of central sensitization during formalin induced acute nociception via attenuation of ERK1/2-NF $\kappa$ B signaling and glial activation," Neurochemistry International, vol. 134, p. 104652, 2020.

[12] H. Y. Jung, S. H. Oh, J. S. Ahn et al., "NOX1 inhibition attenuates kidney ischemia-reperfusion injury via inhibition of ROS-mediated ERK signaling," International Journal of Molecular Sciences, vol. 21, no. 18, p. 6911, 2020.

[13] D. Turnheim, "The OECD policy for the implementation of the principles of good laboratory practice," Annali dell'Istituto Superiore di Sanità, vol. 30, no. 4, pp. 395-400, 1994.

[14] Food, Drug Administration, HHS, "International Conference on Harmonisation; Guidance on M3(R2) Nonclinical Safety Studies for the Conduct of Human Clinical Trials and Marketing Authorization for Pharmaceuticals; availability. Notice," Federal register, vol. 75, pp. 3471-3472, 2010.

[15] M. F. Cesta, D. E. Malarkey, R. A. Herbert et al., "The National Toxicology Program Web-based nonneoplastic lesion atlas: a global toxicology and pathology resource," Toxicologic pathology, vol. 42, no. 2, pp. 458-460, 2014.

[16] M. Sedeek, R. Nasrallah, R. M. Touyz, and R. L. Hebért, "NADPH oxidases, reactive oxygen species, and the kidney: friend and foe," Journal of the American Society of Nephrology, vol. 24, pp. 1512-1518, 2013.

[17] J. L. Arbiser, J. Petros, R. Klafter et al., "Reactive oxygen generated by Nox1 triggers the angiogenic switch," Proceedings of the National Academy of Sciences of the United States of America, vol. 99, no. 2, pp. 715-720, 2002.

[18] G. Gavazzi, B. Banfi, C. Deffert et al., "Decreased blood pressure in NOX1-deficient mice," FEBS Letters, vol. 580, no. 2, pp. 497-504, 2006.

[19] A. Sadok, V. Bourgarel-Rey, F. Gattacceca, C. Penel, M. Lehmann, and H. Kovacic, "Nox1-dependent superoxide production controls colon adenocarcinoma cell migration," 
Biochimica et Biophysica Acta, vol. 1783, no. 1, pp. 23-33, 2008.

[20] V. Braunersreuther, F. Montecucco, M. Ashri et al., "Role of NADPH oxidase isoforms NOX1, NOX2 and NOX4 in myocardial ischemia/reperfusion injury," Journal of Molecular and Cellular Cardiology, vol. 64, pp. 99-107, 2013.

[21] Y. Cui, Y. Wang, G. Li et al., “The Nox1/Nox4 inhibitor attenuates acute lung injury induced by ischemia-reperfusion in mice," PLoS One, vol. 13, no. 12, article e0209444, 2018.

[22] J. L. Wilkinson-Berka, D. Deliyanti, I. Rana et al., "NADPH oxidase, NOX1, mediates vascular injury in ischemic retinopathy," Antioxidants \& Redox Signaling, vol. 20, no. 17, pp. 2726-2740, 2014.

[23] F. De Logu, R. Nassini, S. Materazzi et al., "Schwann cell TRPA1 mediates neuroinflammation that sustains macrophage-dependent neuropathic pain in mice," Nature Communications, vol. 8, no. 1, p. 1887, 2017.

[24] I. M. Marone, F. de Logu, R. Nassini et al., "TRPA1/NOX in the soma of trigeminal ganglion neurons mediates migrainerelated pain of glyceryl trinitrate in mice," Brain, vol. 141, no. 8, pp. 2312-2328, 2018.

[25] B. Thoolen, F. J. W. ten Kate, P. J. van Diest, D. E. Malarkey, S. A. Elmore, and R. R. Maronpot, "Comparative histomorphological review of rat and human hepatocellular proliferative lesions," Journal of Toxicologic Pathology, vol. 25, no. 3, pp. 189-199, 2012.

[26] H. Sung and E. Lee, "Single-dose intramuscular toxicity of Mahwangcheonoh pharmacopuncture in a rat model: - toxicity of Mahwangcheonoh pharmacopuncture in SD rats," Journal of pharmacopuncture, vol. 19, no. 4, pp. 336-343, 2016.

[27] M. A. Miller, "Gender-based differences in the toxicity of pharmaceuticals-the Food and Drug Administration's perspective," International Journal of Toxicology, vol. 20, no. 3, pp. 149-152, 2001. 